Original Research Paper

\title{
Drug-Protein Interactions for Clinical Research by Nucleic Acid Programmable Protein Arrays-Quartz Crystal Microbalance with Dissipation Factor Monitoring Nanoconductometric Assay
}

\author{
${ }^{1,2,3}$ Claudio Nicolini, ${ }^{1,2}$ Rosanna Spera, ${ }^{1,2}$ Nicola Luigi Bragazzi and ${ }^{1,2}$ Eugenia Pechkova \\ ${ }^{I}$ Nanoworld Institute, Fondazione EL.B.A. Nicolini (FEN), Largo Redaelli 7, 24020, Pradalunga, Bergamo, Italy \\ ${ }^{2}$ Laboratories of Biophysics and Nanobiotechnology (LBN), Department of Experimental Medicine (DIMES), \\ University of Genoa, Via Pastore 3, 16132, Genova, Italy \\ ${ }^{3}$ Virginia G. Piper Center for Personalized Diagnostics, Biodesign Institute, Arizona State University (ASU), \\ Tempe, Arizona 85287, United States
}

\begin{abstract}
Article history
Received 2014-10-16;

Revised 2014-11-17;

Accepted 2014-11-20

Corresponding Author:

Claudio Nicolini,

Nanoworld Institute, Fondazione

EL.B.A. Nicolini (FEN), Largo

Redaelli 7, 24020, Pradalunga,

Bergamo, Italy

Fax: $+39-035767215$

Tel.: +39-035767217

E-mail:

president@fondazioneelbanicolini.org
\end{abstract}

\begin{abstract}
Conductometric monitoring of drug-gene and drug-protein interactions is of fundamental importance in the field of molecular pharmacology. Here, we present our main findings and characterizations of an important antiblastic used in neuro-oncology (Temozolomide), interacting with selected proteins that represent predictive biomarkers of the rate survival of the patients, of the outcome of chemotherapy and resistance to drug itself (namely, BRIP1 and MLH1). We use our previously introduced two genes along with previously described Nucleic Acid Programmable Protein Arrays (NAPPA)-based nanoconductometric sensor. We performed a positive control (Temozolomide plus MLH1 protein), a negative control (Temozolomide plus BRIP1 protein) and a multi-gene experiment (Temozolomide plus BRIP1\&MLH1 being coexpressed), showing that we are able to properly perform pharmacoproteomics tasks, discriminating each protein and drug unique conductance curve as well as their interactions, even in the presence of multi-proteins being immobilized. Moreover, in the last part of our paper, we used a multiple regression model in order to predict the behavior of Temozolomide when exposed to BRIP1\&MLH1 co-expressed and we showed that we are able to predict the drug-protein interaction profile with a good regression coefficient.
\end{abstract}

Keywords: Conductometric Sensor, Nucleic Acid Programmable Protein Array (NAPPA), Quartz Crystal Microbalance with Dissipation Factor Monitoring (QCM_D), Cell Free Expression System, Temozolomide, Cancer, Pharmacoproteomics

\section{Introduction}

Gene-drug (Gottlieb and Altman, 2014; Penrod and Moore, 2014) and protein-drug (Jain, 2004; Witzmann and Grant, 2003) interactions play a major role in the field of molecular pharmacology, as a detailed understanding of these interactions is essential for a proper drug development and delivery. In particular, pharmacodynamics and pharmacokinetics of antiblastics are of high clinical interest (Xie et al., 2014), as cancer is one of the major issues to be still addressed in the field of clinical biomedicine (Robert et al., 2014).

Brain tumor, accounting for $2 \%$ of primary tumors (Furnari et al., 2007), is a particularly rapidly aggressive and fatal tumor: World Health Organization (WHO) grade IV malignant glioma, termed as Glioblastoma Multiforme (GBM) is indeed characterized by a median survival of 14.6 months (Stupp et al., 2005). The average incidence rate of GBM is 3.19 cases per 100,000 patientyears (Thakkar et al., 2014), with a range of 3-5 cases per 100,000 patient-years (Thon et al., 2013). The median age of diagnosis is 64 years (Thakkar et al., 2014; Thon et al., 2013); rarely, in less than 5\% of the cases, GBM develops in younger patients (secondary GBM), having different clinical and epidemiological features (Adamson et al., 2009; Furnari et al., 2007; Thon et al., 2013). GBM affects more males than females and involves whites more than blacks or Asians 
(Dubrow and Darefsky, 2011; Thakkar et al., 2014; Thon et al., 2013). Some favorable clinical prognostic factors have been identified and include: Younger age, cerebellar location, good Karnofsky performance status and maximal tumor surgical resection (Thakkar et al., 2014). From a molecular point of view, biomarkers such as O6-Methylguanine-DNA Methyltransferase (MGMT) methylation, Isocitrate Dehydrogenase type 1 and type 2 (IDH1/2) mutation (Megova et al., 2014) and glioma Cytosine-phosphate-Guanine (CpG) Island Methylator Phenotype (G-CIMP) (Noushmehr et al., 2010; Ostrom et al., 2014) can predict better survival.

Despite extensive investigation, the etiopathogenesis of GBM is not clear. Some authors speculate that some infectious agents, such as cytomegalovirus (Cobbs, 2013; Thon et al., 2013) or Human Papillomavirus (HPV) (Vidone et al., 2014), may drive the neoplastic process, while other scholars think that occupational exposures to ionizing radiation, the more widespread usage of cellular phones, or a decrease in risk by history of allergies could lead to tumorigenesis. (Ostrom et al., 2014). Others think of incorrect nutritional and eating behaviors (Sandrone et al., 2014). What is known is that only a small percentage of these tumors (less than 1\%) is due to Mendelian pathologies, such as neurofibromatosis type 1 and type 2, tuberous sclerosis, Turcot's syndrome, Gorlin syndrome, melanoma-astrocytoma syndrome and $\mathrm{Li}$ Fraumeni syndrome (Malmer et al., 2007; Ostrom et al., 2014). Summarizing, under the same umbrella of GBM many heterogeneous diseases are included, characterized by the involvement of different genetic pathways and by different clinical prognostic outcomes (Patel et al., 2014; Rodriguez-Hernandez et al., 2014; Thakkar et al., 2014).

The current standard of care and treatment for patients with GBM include maximal safe surgical resection, followed by concurrent fractionated Radiation Therapy (RT) to the resection cavity (60 Gy, over 6 weeks) and chemotherapy (with temozolomide (TMZ), followed by adjuvant TMZ) (Stupp et al., 2005; Weathers and Gilbert, 2014).

Despite this highly integrated multimodal, multidisciplinary approach, more than half of the tumors are resistant to this therapy and there is an urgent need to develop novel, effective treatments. Experimental therapies are based on oncolytic herpes simplex virus (Ning and Wakimoto, 2014), administration of monoclonal antibodies (such as bevacizumab, cetuximab, imatinib, gefitinib, erlotinib, cedarinib, sunitinib and vatalanib, among the others), new drugs such as cilengitide, Laser Interstitial Thermal Therapy (LITT), or immunotherapy. For a complete review concerning the different therapeutic options, the reader is referred to (Furnari et al., 2007).
TMZ (brand name Temodar, Temodal and Temcad) is an oral antiblastic, chemically being the imidazotetrazine derivative of the alkylating/methylating agent dacarbazine and it undergoes rapid chemical conversion in the systemic circulation at physiological $\mathrm{pH}$ to the active compound, 3-Methyl-(triazen-1-yl) Imidazole-4-Carboxamide (MTIC). TMZ is useful for treating brain tumors, such as the GBM, the relapsed Grade III anaplastic astrocytoma, especially if nitrosourea- and procarbazine-refractory, as well as skin cancers, like the melanoma and the fungoides mycosis/Sézary syndrome (Querfeld et al., 2011). It is currently in evaluation for the treatment of other tumors, such as the relapsed primary CNS lymphoma, recurrent glioma and oligodendroglioma (in the last case, replacing the classical regimen Procarbazine-LomustineVincristine (PCV)). When it binds to the DNA, usually at the N-7 or O-6 positions of guanine residues, it produces $\mathrm{O}(6)-$ Methylguanine (O6MG) and this abduct causes the activation of futile DNA Mismatch Repair (MMR), as well as DNA Double-Strand Breaks (DSBs), G(2) arrest and ultimately cell death. The activation of the molecular mechanisms of MMR is quite a complex biological process that required different protein-protein interactions, such as the Mre11/Rad50/Nbs1 (MRN complex), the Proliferating Cellular Nuclear Antigen (PCNA) complex and the gamma-H2AX and 53BP1 foci (Mirzoeva et al., 2006).

Unfortunately, some cells can escape from this mechanisms, producing a protein known as O6alkylguanine DNA Alkyltransferase (AGT) and encoded by the O-6-Methylguanine-DNA Methyltransferase (MGMT) gene. Recently, scientists have been able to find and characterize some biomarkers of resistance to TMZ, such as MLH1, which is also an important marker of survival rate in patients with glioblastoma (Mirzoeva et al., 2006; Querfeld et al., 2011; Shinsato et al., 2013; Stark et al., 2010; von Bueren et al., 2012).

In the last years, the evolution of the nanobiotechnologies applied to proteins, namely proteomics, both structural and functional and specifically the development of more sophisticated protein arrays, has enabled scientists to investigate protein interactions and functions with an unforeseeable precision and wealth of details (Nicolini et al., 2012a; 2012b; Nicolini et al., 2013). Moreover, protein arrays can be coupled with label-free approaches: The so-called cell-free protein arrays (Bragazzi et al., 2014b; Dixon, 2008; Fee, 2013; Hunter, 2009; Spera et al., 2013).

In this manuscript, we report and discuss some preliminary results of protein expression of genes related to cancer and in particular to brain tumors and GBM. Experiments have been carried out coupling Nucleic Acid Programmable Protein Array (NAPPA) 
with a recently improved nanogravimetric apparatus which exploits the Quartz Crystal Microbalance with Frequency (QCM_F) and quartz Crystal Microbalance with Dissipation Monitoring (QCM_D) technologies (Nicolini et al., 2012a; Spera et al., 2013). The selected proteins are BRIP1 and MLH1 and their role and biological roles will be discussed further in this manuscript.

We chose NAPPA since this innovative technology avoids any time-consuming task in the difficult process of obtaining highly purified proteins, relying instead on the production of proteins from high quality supercoiled DNA. For this purpose, complementary DNAs (cDNAs) of selected genes tagged with a C-terminal Glutathione S-Transferase (GST) are spotted on the microarray surface and expressed using a cell-free transcription/translation system (IVTT, in vitro transcription and translation). The newly expressed protein is captured on the array by an anti-GST antibody that have been co-immobilized with the expression clone on the microarray surface.

The advantages and benefits of NAPPA technologies can be briefly summarized (Spera et al., 2013):

- The demanding process of obtaining highly purified proteins is replaced by a single quick step; furthermore, cDNAs and clones are more easily available

- Proteins expressed on the NAPPA arrays are stable, properly folded and biologically, functionally active

NAPPA microarrays can be useful in biomarkers discovery and for other clinical applications, such as biosensor development, especially in the effort of moving towards Personalized Medicine. For this task we coupled NAPPA with a new generation of conductometric devices, namely QCM. QCM_D indeed appears a promising tool to study protein-protein interactions especially in the field of oncology, both cellular and molecular (Cheng et al., 2012).

To the best of our knowledge, we coupled for the first time QCM_D with NAPPA technology for biomedical applications in the field of neuro-oncology. Moreover, there are few biosensors developed for GBM, usually for cellular sensing (Beljebbar et al., 2010; Brasuel et al., 2001; Chen et al., 2008; Desai et al., 2006; Manning et al., 1998; Trevin et al., 1998; Valero et al., 2010; Zakir Hossain et al., 2007). The objective of the present research regards the analysis of protein-drug and multiple protein-drug interaction towards potentially useful clinical applications, namely in the field of cancer studies.

Clinical implications are also envisaged and addressed.

\section{Materials and Methods}

\section{QCM_D Conductometer}

Nanogravimetry makes use of functionalized piezoelectric Quartz Crystals (QC), which vary their resonance frequency $(f)$ when a mass $(m)$ is adsorbed to or desorbed from their surface. This is well described by the well-known Sauerbrey's equation:

$$
\Delta \mathrm{f} / \mathrm{f}_{0}=-\mathrm{m} / \mathrm{A} \rho \mathrm{l}
$$

where, $f_{0}$ is the fundamental frequency, $A$ is the surface area covered by the adsorbed molecule and $\rho$ and 1 are the quartz density and thickness, respectively.

Quartz resonators response strictly depends on the biophysical properties of the analyte, such as the viscoelastic coefficient. The dissipation factor (D) of the crystal's oscillation is correlated with the softness of the studied material and its measurement can be computed by taking into account the bandwidth of the conductance curve $2 \Gamma$, according to the following equation:

$$
D=2 \Gamma / f
$$

where, $f$ is the peak frequency value.

In our analysis we introduced also a "normalized D factor", $D_{N}$, that we defined as the ratio between the halfwidth half-maximum $(\Gamma)$ and the half value of the maximum value of the conductance $\left(G_{\max }\right)$ of the measured conductance curves (Spera et al., 2013):

$$
D_{N}=2 \Gamma / G_{\max }
$$

$D_{N}$ is more strictly related to the curve shape, reflecting the conductance variation (Bragazzi et al., 2014a; Spera et al., 2013).

\section{NAPPA Experiments}

The QCM_D instrument was developed by Elbatech (Elbatech srl, Marciana-LI, Italy). The quartz was connected to an RF gain-phase detector (Analog Devices, Inc., Norwood, MA, USA) and was driven by a precision DDS (Analog Devices, Inc., Norwood, MA, USA) around its resonance frequency, thus acquiring a conductance versus frequency curve ("conductance curve") which shows a typical Gaussian behaviour. The conductance curve peak was at the actual resonance frequency while the shape of the curve indicated how the viscoelastic effects of the surrounding layers affected the oscillation. The QCM_D software, QCMAgic-Q5.3.256 (Elbatech srl, Marciana-LI, Italy) allows to acquire the conductance curve or the frequency and dissipation 
factor variation versus time. In order to have a stable control of the temperature, the experiments were conducted in a temperature chamber. Microarrays were produced on standard nanogravimetry quartz used as highly sensitive transducers. The QC expressing proteins consisted of $9.5 \mathrm{MHz}$, AT-cut quartz crystal of $14 \mathrm{~mm}$ blank diameter and $7.5 \mathrm{~mm}$ electrode diameter, produced by ICM (Oklahoma City, USA). The electrode material was $100 \AA \mathrm{Cr}$ and $1000 \AA \mathrm{Au}$ and the quartz was (Nicolini et al., 2012b; Spera et al., 2013).

The NAPPA-QC arrays were printed with 100 spots per QC.

Quartzes gold surfaces were coated with cysteamine to allow the immobilization of the NAPPA printing mix. Briefly, quartzes were washed three times with ethanol, dried with Argon and incubated over night at $4^{\circ} \mathrm{C}$ with $2 \mathrm{mM}$ cysteamine. Quartzes were then washed three times with ethanol to remove any unbound cysteamine and dried with Argon. Plasmids DNA coding for GST tagged proteins were transformed into E. coli and DNA were purified using the NucleoPrepII anion exchange resin (Macherey Nagel). NAPPA printing mix was prepared with $1.4 \mu \mathrm{g} \mathrm{uL}^{-1}$ DNA, $3.75 \mu \mathrm{g} \mathrm{uL}^{-1}$ BSA (Sigma-Aldrich), $5 \mathrm{mM}$ BS3 (Pierce, Rockford, IL, USA) and $66.5 \mu \mathrm{g}$ polyclonal capture GST antibody (GE Healthcares). Negative controls, named master mix (hereinafter abbreviated as "MM"), were obtained replacing DNA for water in the printing mix. Samples were incubated at room temperature for $1 \mathrm{~h}$ with agitation and then printed on the cysteamine-coated gold quartz using the Qarray II from Genetix. In order to enhance the sensitivity, each quartz was printed with 100 identical features of 300 microns diameter each, spaced by 350 microns center-to-center. The human cDNAs immobilized on the NAPPA-QC were: MLH1 (mutL homolog 1) and BRIP1 (BRCA1 interacting protein $\mathrm{C}$-terminal helicase 1).

Gene expression was performed immediately before the assay, following the protocol described in (Spera et al., 2013). Briefly, IVTT was performed using HeLa lysate mix (1-Step Human Coupled IVTT Kit, Thermo Fisher Scientific Inc.), prepared according to the manufacturers' instructions. The quartz, connected to the nanogravimeter inside the incubator, was incubated for $10 \mathrm{~min}$ at $30^{\circ} \mathrm{C}$ with $40 \mu \mathrm{L}$ of HeLa lysate mix for proteins synthesis and then, the temperature was decreased to $15^{\circ} \mathrm{C}$ for a period of $5 \mathrm{~min}$ to facilitate the proteins binding on the capture antibody (anti-GST). After the protein expression and capture, the quartz was removed from the instrument and washed at room temperature, in $500 \mathrm{mM} \mathrm{NaCl}$ PBS for 3 times. The protocol described above was followed identically for both negative control QC (the one with only MM, i.e., all the NAPPA chemistry except the cDNA) and protein displaying QC.

After protein expression, capture and washing the QCs were used for the interaction studies QC displaying the expressed protein was spotted with 40 $\mu 1$ of drug solutions in PBS at increasing concentrations at $22^{\circ} \mathrm{C}$.

Reproducibility of the experiments was assessed computing the Coefficient of Variation $\left(\mathrm{CV}\right.$, or $\left.\sigma^{*}\right)$, using the following equation:

$$
\sigma^{*}=\sigma / \mu
$$

where, $\sigma$ is the standard deviation and $\mu$ is the mean.

We also tested the possibility to analyze drug-protein interactions in QC displaying multiple proteins. For this aim, we co-printed cDNA for BRIP1\&MLH1 on a single QC. We analyzed the interaction response to TMZ on both NAPPA-expressed QCs.

We analyzed the interaction between BRIP1, MLH1 and TMZ drug solutions at different concentrations to analyze the binding kinetics after protein expression and capture the expressing QC was spotted, in sequence, with $40 \mu \mathrm{L}$ of increasing Temozolomide solutions of concentration: 1, 2, 5, 10, 20, 50, 100 and $200 \mu \mathrm{g} \mathrm{mL}^{-1}$. As negative control we analyzed the interaction between BRIP1/FANCJ, a helicase initially linked to breast cancer (Cantor and Xie, 2010) and to Fanconi anemia and TMZ, while MLH1, which is a protein involved in DNA mismatches repair, is known to interact with TMZ.

\section{Results and Discussion}

QCM_D measures were calibrated for frequency and for $\mathrm{D}$ factor shifts. The calibration curves equation (obtained with Ordinary Least Squares methods, OLS) are:

$$
\Delta f=-7.16-231.18 \mathrm{~m} ; \text { with } \mathrm{r}^{2}=0.9986
$$

And:

$$
\mathrm{D}=0.831+0.286 \eta ; \text { with } \mathrm{r}^{2}=0.9990 \text {. }
$$

We analyzed the conductance curves acquired in NAPPA-QCs in different steps of the expressing and capturing process: After the addition of human IVTT lysate at $30^{\circ} \mathrm{C}$ ("IVTT addition"), i.e., prior protein expression; after $10 \mathrm{~min}$ from the addition of human IVTT lysate, i.e., after protein expression ("IVTT 
addition 10 min"); after the final washing process with PBS ("Post-wash").

In Fig. 1 are reported the conductance curves of increasing concentrations of TMZ spotted on quartz blanks, while in Fig. 2 are shown the conductance curves of quartz carrying MLH1 gene being expressed and thereafter interacting with TMZ solutions at increasing concentrations are reported.

Figure 3 shows the response to increasing concentrations of TMZ: Since MLH1 interacts with the drug, this response is linear up to $200 \mu \mathrm{g} \mathrm{mL}^{-1}$.

Figure 4 shows the conductance curves for NAPPAQCs expressing BRIP1. We analyzed the interaction among BRIP1 and TMZ, verifying that the protein does not interact with the drug.
Figure 5 reports the conductance curves for NAPPAQCs carrying BRIP1\&MLH1 being co-immobilized. Figure 6 shows the response to increasing concentrations of TMZ: We reproduce the behavior shown in Fig 4, even though with an exponential fit.

These data pointed to a unique conductance curve shape for each protein and suggested the possibility to identify the expressed proteins by QCM-D even when combined on the same expressing QC (Fig 7).

In Table 1-3 are reported the main parameters of the conductance curves of Fig 2, 4 and 5, respectively.

In Table 4 and 5 are reported the two multiple regression models that have been used to predict the behavior of the multi-gene experiment (MM_BRIP1\&MLH1 interacting with TMZ).

Table 1. Main parameters of QC-NAPPA displaying MM_MLH1 plus temozolomide (as positive control) ${ }^{\mathrm{a}}$

\begin{tabular}{|c|c|c|c|c|c|}
\hline Conductance curves & $\mathrm{f}(\mathrm{Hz})^{\mathrm{b}}$ & $\Gamma(\mathrm{Hz})^{\mathrm{b}}$ & $\mathrm{G}_{\max }(\mathrm{mS})^{\mathrm{b}}$ & $\mathrm{D} \times 10^{3 \mathrm{c}}$ & $\mathrm{D}_{\mathrm{N}}(\mathrm{Hz} / \mathrm{mS})^{\mathrm{c}}$ \\
\hline \multicolumn{6}{|l|}{ MM_MLH1 } \\
\hline Beginning & 9492064 & 3156 & 0.72 & 0.33 & 4402.90 \\
\hline IVTT addition & 9485902 & 8112 & 0.65 & 0.86 & 12464.66 \\
\hline IVTT addition $10 \mathrm{~min}$ & 9485164 & 12564 & 0.64 & 1.32 & 19742.30 \\
\hline post capture & 9484642 & 9444 & 0.63 & 1.00 & 15009.54 \\
\hline post wash & 9481762 & 13236 & 0.48 & 1.40 & 27748.43 \\
\hline \multicolumn{6}{|c|}{ MM_MLH1 plus Temozolomide } \\
\hline Temozolomide $1 \mu \mathrm{g} \mathrm{mL}^{-1}$ & 9484546 & 17076 & 0.29 & 1.80 & 58882.76 \\
\hline Temozolomide $2 \mu \mathrm{g} \mathrm{mL}^{-1}$ & 9482608 & 13548 & 0.26 & 1.43 & 52027.65 \\
\hline Temozolomide $5 \mu \mathrm{g} \mathrm{mL}^{-1}$ & 9483514 & 14604 & 0.22 & 1.54 & 64993.32 \\
\hline Temozolomide $10 \mathrm{~mL}$ & 9483514 & 14472 & 0.22 & 1.53 & 64463.25 \\
\hline Temozolomide $20 \mu \mathrm{g} \mathrm{mL}^{-1}$ & 9484006 & 15288 & 0.20 & 1.61 & 77212.12 \\
\hline Temozolomide $50 \mu \mathrm{g} \mathrm{mL}^{-1}$ & 9483664 & 14028 & 0.17 & 1.48 & 83005.92 \\
\hline Temozolomide $100 \mu \mathrm{g} \mathrm{mL}^{-1}$ & 9483766 & 13920 & 0.16 & 1.47 & 89059.50 \\
\hline Temozolomide $200 \mu \mathrm{g} \mathrm{mL}^{-1}$ & 9482098 & 9480 & 0.06 & 1.00 & 167491.20 \\
\hline
\end{tabular}

${ }^{a}$ Conductance curves were collected in different steps of NAPPA protocol. ${ }^{b} \mathrm{f}$ is peak frequency, $\Gamma$ is the half-width half-maximum $(\mathrm{HWHM})$ and $\mathrm{G}_{\max }$ is the maximum conductance. ${ }^{c} \mathrm{D}$ factor and $\mathrm{D}_{\mathrm{N}}$ (computed as $\mathrm{D}_{\mathrm{N}}=2 \Gamma / \mathrm{G}_{\max }$ ) normalized $\mathrm{D}$ factor

Table 2. Main parameters of QC-NAPPA displaying MM_BRIP1 plus temozolomide (as negative control) ${ }^{\mathrm{a}}$

\begin{tabular}{|c|c|c|c|c|c|}
\hline Conductance curves & $\mathrm{f}(\mathrm{Hz})^{b}$ & $\Gamma(\mathrm{Hz})^{\mathrm{b}}$ & $\mathrm{G}_{\max }(\mathrm{mS})^{\mathrm{b}}$ & $\mathrm{D} \times 10^{3 \mathrm{c}}$ & $\mathrm{D}_{\mathrm{N}}(\mathrm{Hz} / \mathrm{mS})^{\mathrm{c}}$ \\
\hline Beginning & 9490798 & 2772 & 0.71 & 0.29 & 3911.94 \\
\hline IVTT addition & 9485806 & 7056 & 0.65 & 0.74 & 10867.09 \\
\hline IVTT addition 10 minutes & 9485026 & 7392 & 0.64 & 0.78 & 11517.61 \\
\hline post capture & 9484612 & 7644 & 0.64 & 0.81 & 12015.09 \\
\hline post wash & 9481036 & 8844 & 0.13 & 0.93 & 66396.40 \\
\hline Temozolomide $1 \mu \mathrm{g} \mathrm{mL}^{-1}$ & 9480568 & 8352 & 0.12 & 0.88 & 67902.44 \\
\hline Temozolomide $2 \mu \mathrm{g} \mathrm{mL}^{-1}$ & 9482452 & 11016 & 0.11 & 1.16 & 102857.10 \\
\hline Temozolomide $5 \mu \mathrm{g} \mathrm{mL}^{-1}$ & 9482434 & 11616 & 0.11 & 1.23 & 104366.60 \\
\hline Temozolomide $10 \mu \mathrm{g} \mathrm{mL}^{-1}$ & 9482224 & 11352 & 0.11 & 1.20 & 99841.69 \\
\hline Temozolomide $20 \mu \mathrm{g} \mathrm{mL}^{-1}$ & 9482248 & 10740 & 0.11 & 1.13 & 100939.80 \\
\hline Temozolomide $50 \mu \mathrm{g} \mathrm{mL}^{-1}$ & 9481720 & 9600 & 0.10 & 1.01 & 98461.54 \\
\hline Temozolomide $100 \mu \mathrm{g} \mathrm{mL}^{-1}$ & 9482542 & 11016 & 0.09 & 1.12 & 113724.70 \\
\hline Temozolomide $200 \mu \mathrm{g} \mathrm{mL}^{-1}$ & 9481978 & 9600 & 0.08 & 1.01 & 121827.40 \\
\hline
\end{tabular}

${ }^{a}$ Conductance curves were collected in different steps of NAPPA protocol. ${ }^{b} \mathrm{f}$ is peak frequency, $\Gamma$ is the half-width half-maximum (HWHM) and $G_{\max }$ is the maximum conductance. ${ }^{c} \mathrm{D}$ factor and $\mathrm{D}_{\mathrm{N}}$ (computed as $\mathrm{D}_{\mathrm{N}}=2 \Gamma / \mathrm{G}_{\max }$ ) normalized $\mathrm{D}$ factor 
Table 3. Main parameters of QC-NAPPA displaying MM_BRIP1\&MLH1 plus temozolomide (as multi-genes experiment) ${ }^{\mathrm{a}}$

\begin{tabular}{|c|c|c|c|c|c|}
\hline Conductance curves & $\mathrm{f}(\mathrm{Hz})^{b}$ & $\Gamma(\mathrm{Hz})^{\mathrm{b}}$ & $\mathrm{G}_{\max }(\mathrm{mS})^{\mathrm{b}}$ & $\mathrm{D} \times 10^{3 \mathrm{c}}$ & $\mathrm{D}_{\mathrm{N}}(\mathrm{Hz} / \mathrm{mS})^{\mathrm{c}}$ \\
\hline Beginning & 9494290 & 6084 & 0.65 & 0.64 & 9417.957 \\
\hline IVTT addition & 9488638 & 8184 & 0.65 & 0.86 & 12509.94 \\
\hline IVTT addition $10 \mathrm{~min}$ & 9487816 & 8196 & 0.65 & 0.86 & 12630.61 \\
\hline post capture & 9487516 & 8496 & 0.64 & 0.90 & 13184.36 \\
\hline post wash & 9484360 & 10668 & 0.50 & 1.12 & 21521.08 \\
\hline Temozolomide $1 \mu \mathrm{g} \mathrm{mL}^{-1}$ & 9484210 & 10920 & 0.40 & 1.15 & 27596.66 \\
\hline Temozolomide $2 \mu \mathrm{g} \mathrm{mL}^{-1}$ & 9484486 & 10668 & 0.35 & 1.12 & 30850.20 \\
\hline Temozolomide $5 \mu \mathrm{g} \mathrm{mL}^{-1}$ & 9484654 & 10044 & 0.35 & 1.06 & 28961.94 \\
\hline Temozolomide $10 \mu \mathrm{g} \mathrm{mL}^{-1}$ & 9484834 & 10212 & 0.29 & 1.08 & 35569.49 \\
\hline Temozolomide $20 \mu \mathrm{g} \mathrm{mL}^{-1}$ & 9484336 & 7992 & 0.16 & 0.84 & 49918.80 \\
\hline Temozolomide $50 \mu \mathrm{g} \mathrm{mL}^{-1}$ & 9484108 & 6360 & 0.08 & 0.67 & 81853.28 \\
\hline Temozolomide $100 \mu \mathrm{g} \mathrm{mL}^{-1}$ & 9483412 & 5772 & 0.05 & 0.61 & 125478.30 \\
\hline Temozolomide $200 \mu \mathrm{g} \mathrm{mL}^{-1}$ & 9483316 & 5664 & 0.05 & 0.60 & 122597.40 \\
\hline
\end{tabular}

${ }^{\mathrm{a}}$ Conductance curves were collected in different steps of NAPPA protocol. ${ }^{\mathrm{b}} \mathrm{f}$ is peak frequency, $\Gamma$ is the half-width half-maximum $(H W H M)$ and $G_{\max }$ is the maximum conductance. ${ }^{c} D$ factor and $D_{N}$ (computed as $D_{N}=2 \Gamma / G_{\max }$ ) normalized $D$ factor

Table 4. Multiple regression model predicting the behavior of Temozolomide interacting with BRIP1\&MLH1 co-expressed (dependent variable), being known $\Gamma(\mathrm{Hz})$ of Temozolomide plus MLH1 and $\Gamma(\mathrm{Hz})$ of Temozolomide plus BRIP1 as well as the Temozolomide concentration $(\mu \mathrm{g} / \mathrm{ml})$ (independent variables)

\begin{tabular}{|c|c|c|c|c|c|}
\hline Independent variables & Coefficient & Std. Error & $r_{\text {partial }}$ & $\mathrm{t}$ & p-value \\
\hline (Constant) & 9740.8066 & & & & \\
\hline Temozolomide concentration $(\mu \mathrm{g} / \mathrm{ml})$ & -26.5321 & 7.6756 & -0.8159 & -3.457 & 0.0135 \\
\hline
\end{tabular}

Table 5. Multiple regression model predicting the behavior of Temozolomide interacting with BRIP1\&MLH1 co-expressed (dependent variable), being known $\mathrm{G}_{\max }(\mathrm{mS})$ of Temozolomide plus MLH1 and $\mathrm{G}_{\max }(\mathrm{mS})$ of Temozolomide plus BRIP1 as well as the Temozolomide concentration $(\mu \mathrm{g} / \mathrm{ml})$ (independent variables)

\begin{tabular}{llllll}
\hline Independent variables & Coefficient & Std. Error & $\mathrm{r}_{\text {partial }}$ & $\mathrm{t}$ & $\mathrm{p}$-value \\
\hline$($ Constant $)$ & -0.1405 & & & \\
$\mathrm{G}_{\max }(\mathrm{mS}) \mathrm{MM}$ MLH1 plus Temozolomide & 1.7913 & 0.3983 & 0.8782 & 4.497 & 0.0041 \\
\hline
\end{tabular}

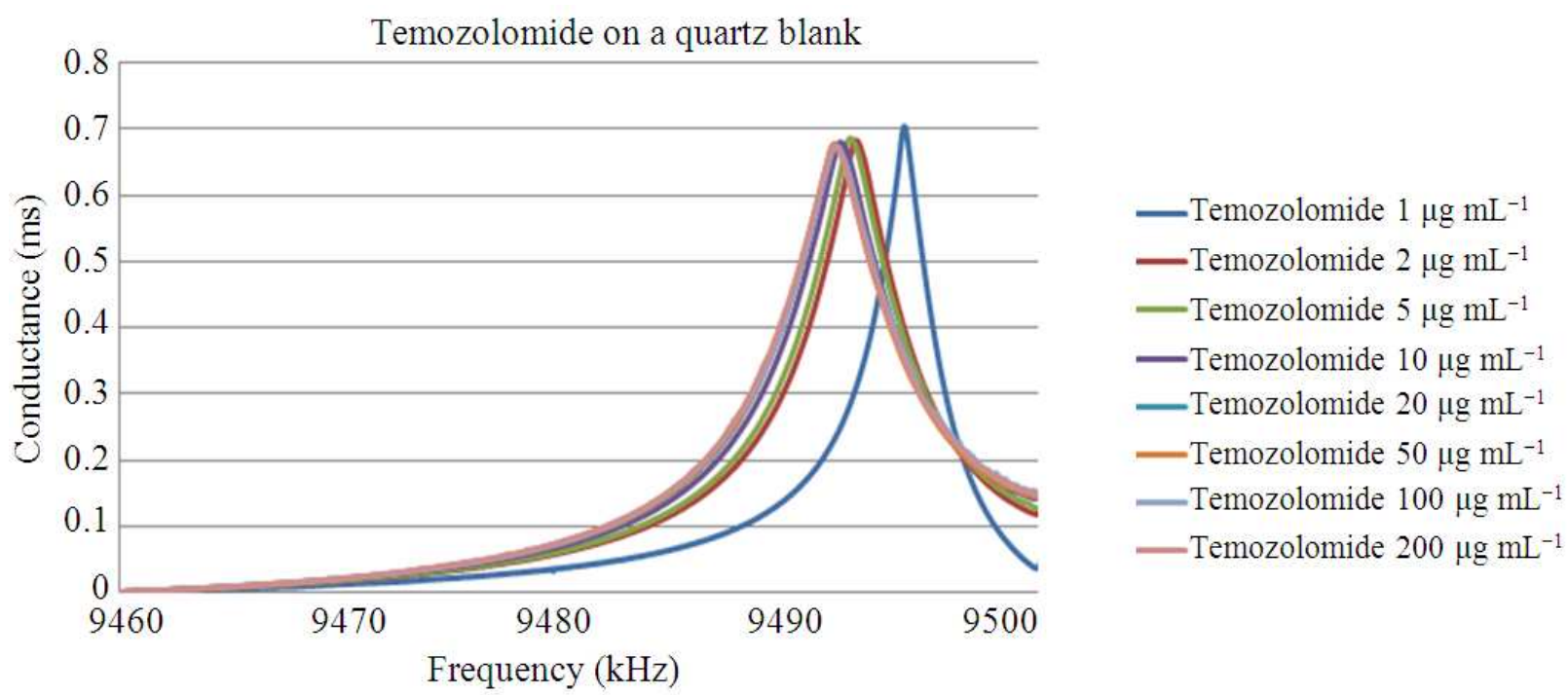

Fig. 1. Conductance curves of Temozolomide on a QC blank (as background). The curves were collected, as reported in the legends, after the addition of increasing concentration of Temozolomide 

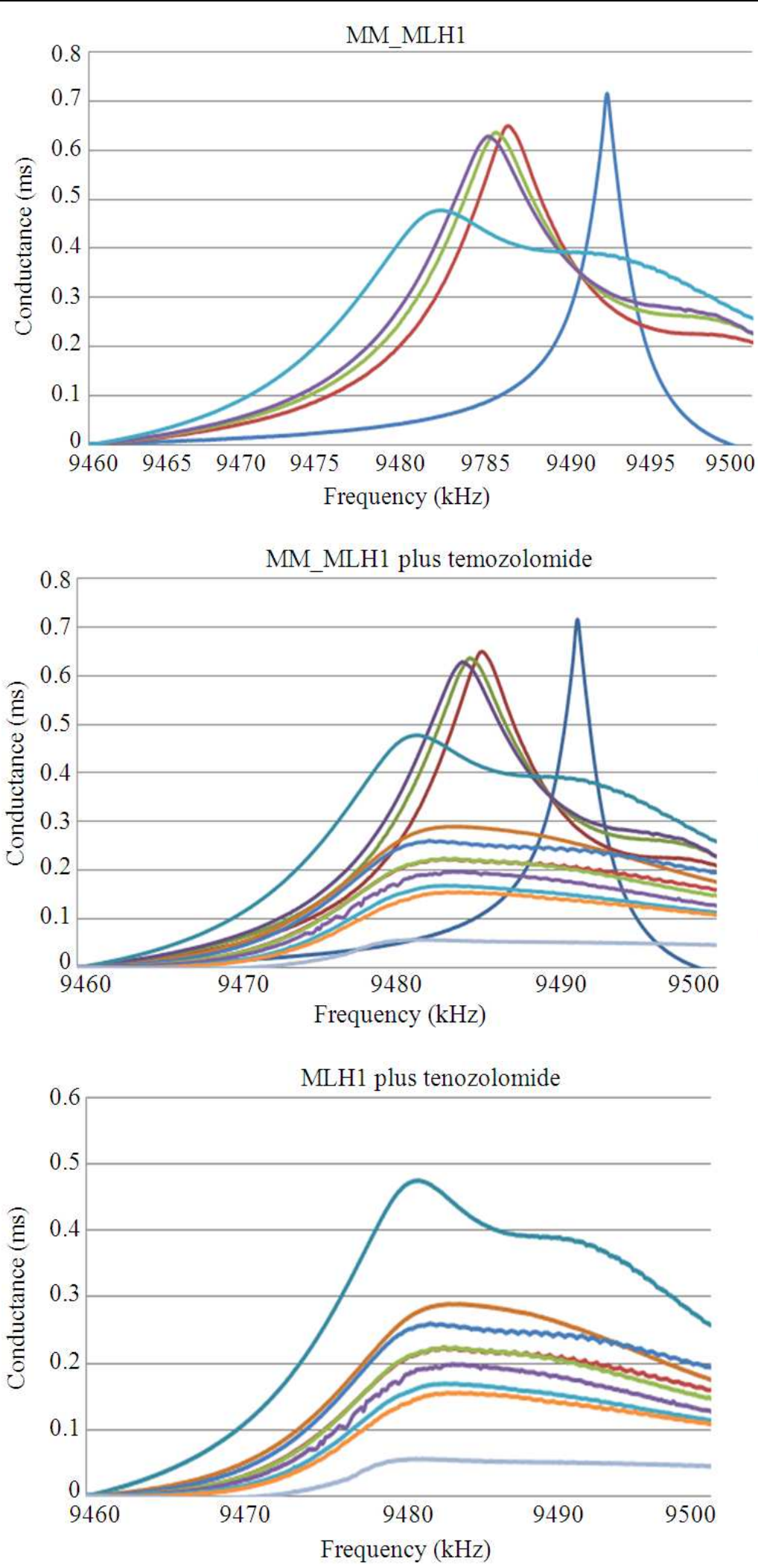

—Beginning

- IVTT addition

—IVTT addition $10 \mathrm{~min}$

- Post capture

— Post wash
- Beginning

— IVTT addition

— IVTT addition $10 \mathrm{~min}$

- Post capture

- Post wash

— Temozolomide $1 \mu \mathrm{g} \mathrm{mL}^{-1}$

- Temozolomide $2 \mu \mathrm{g} \mathrm{mL}^{-1}$

- Temozolomide $5 \mu \mathrm{g} \mathrm{mL}^{-1}$

- Temozolomide $10 \mu \mathrm{g} \mathrm{mL}^{-1}$

- Temozolomide $20 \mu \mathrm{g} \mathrm{mL}^{-1}$

- Temozolomide $50 \mu \mathrm{g} \mathrm{mL}^{-1}$

- Temozolomide $100 \mu \mathrm{g} \mathrm{mL}^{-1}$

— Temozolomide $200 \mu \mathrm{g} \mathrm{mL}-1$
- Post wash

—Temozolomide $1 \mu \mathrm{g} \mathrm{mL}^{-1}$

- Temozolomide $2 \mu \mathrm{g} \mathrm{mL}^{-1}$

—Temozolomide $5 \mu \mathrm{g} \mathrm{mL}^{-1}$

- Temozolomide $10 \mu \mathrm{g} \mathrm{mL}^{-1}$

— Temozolomide $20 \mu \mathrm{g} \mathrm{mL}^{-1}$

- Temozolomide $50 \mu \mathrm{g} \mathrm{mL}^{-1}$

— Temozolomide $100 \mu \mathrm{g} \mathrm{mL}^{-1}$

— Temozolomide $200 \mu \mathrm{g} \mathrm{mL}^{-1}$

Fig. 2. Conductance curves of MM_MLH1 expressing QC (upper panel). Conductance curves of MM_MLH1 expressing QC plus Temozolomide (as positive control) (intermediate and lower panel). The curves were collected in different steps of NAPPA process, as reported in the legends and after the addition of increasing concentration of Temozolomide 

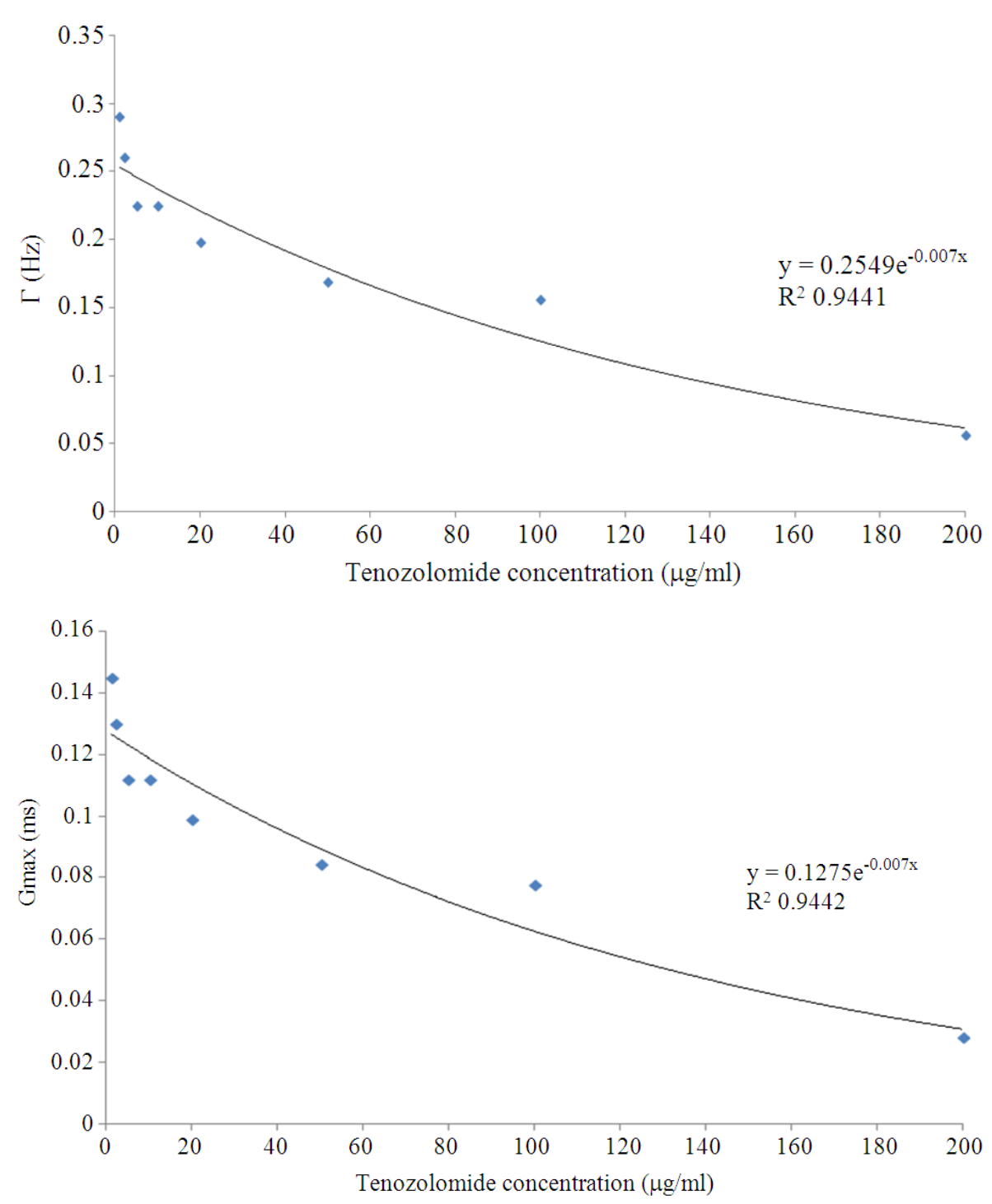

Fig. 3. Linear response to increasing doses of Temozolomide: Correlation between $\Gamma(\mathrm{Hz})$ and Temozolomide concentration $(\mu \mathrm{g} / \mathrm{ml})$ (upper panel); correlation between $\mathrm{G}_{\max }(\mathrm{mS})$ and Temozolomide concentration $(\mu \mathrm{g} / \mathrm{ml})$ (lower panel)

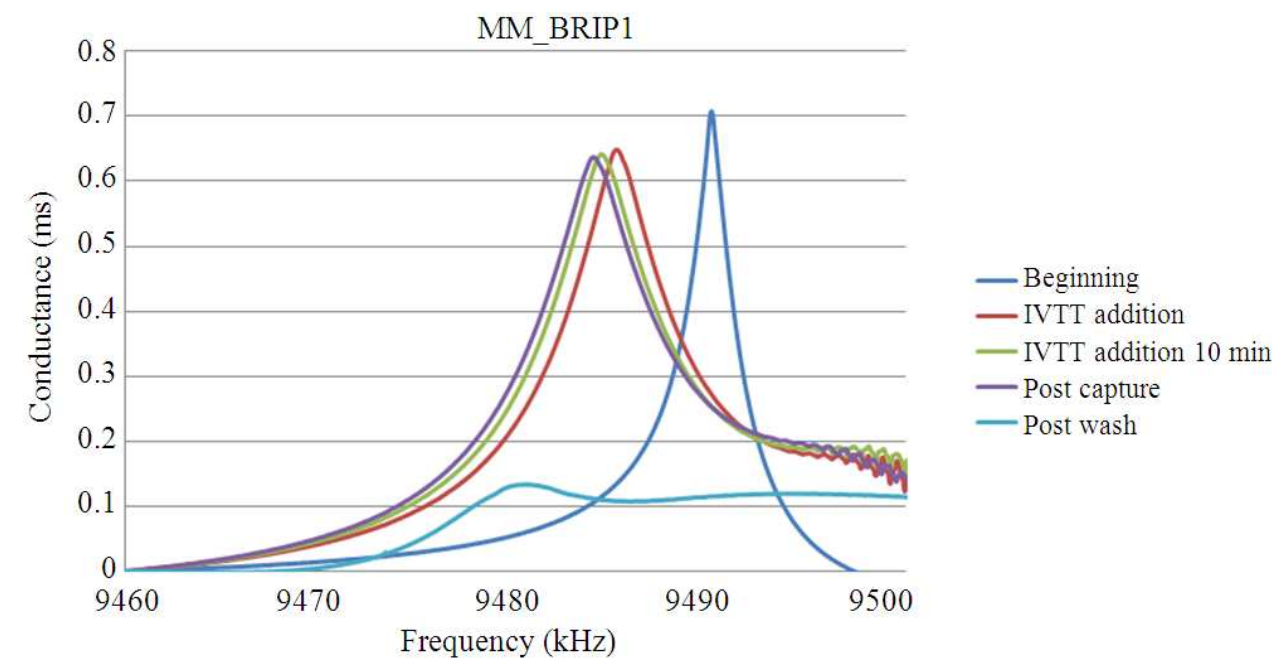



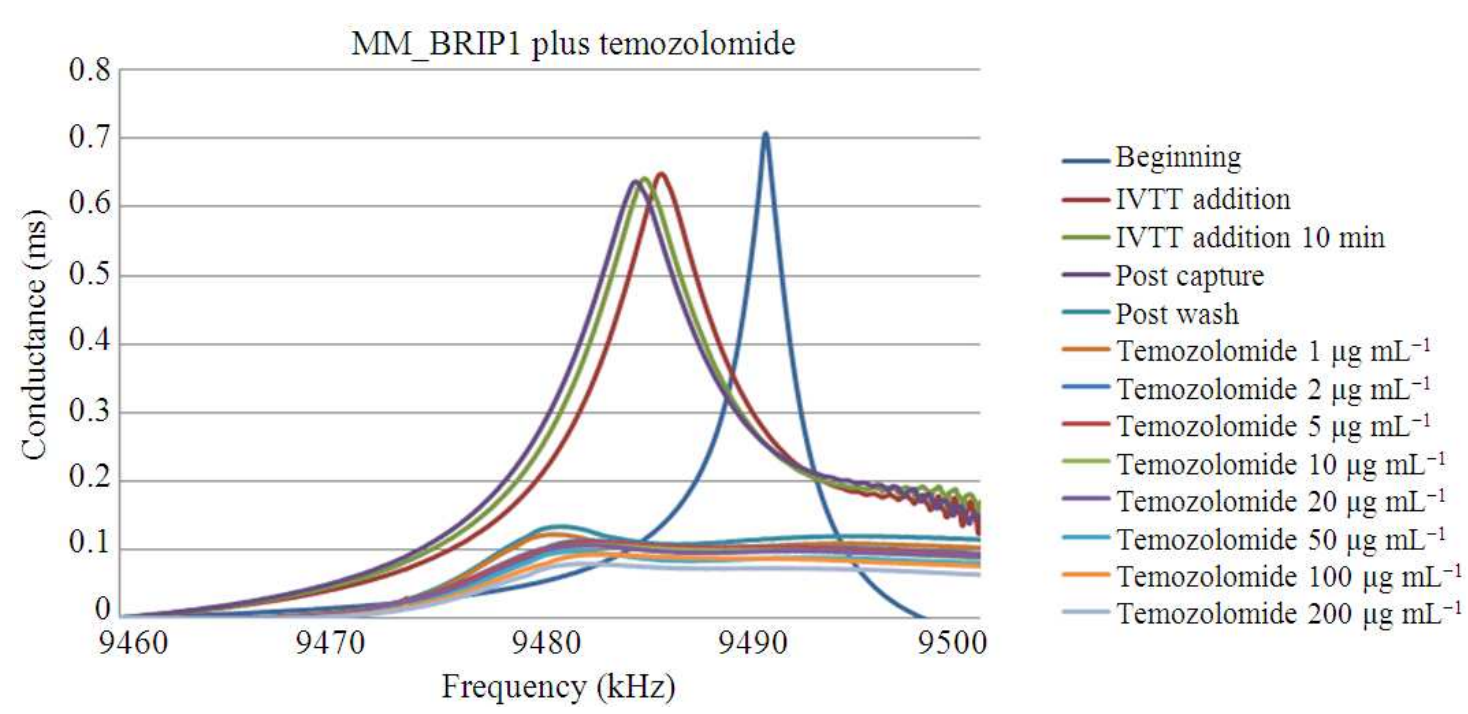

Fig. 4. Conductance curves of MM_BRIP1 expressing QC (upper panel). Conductance curves of MM_BRIP1 expressing QC plus Temozolomide (as negative control) (lower panel). The curves were collected in different steps of NAPPA process, as reported in the legends and after the addition of increasing concentration of Temozolomide
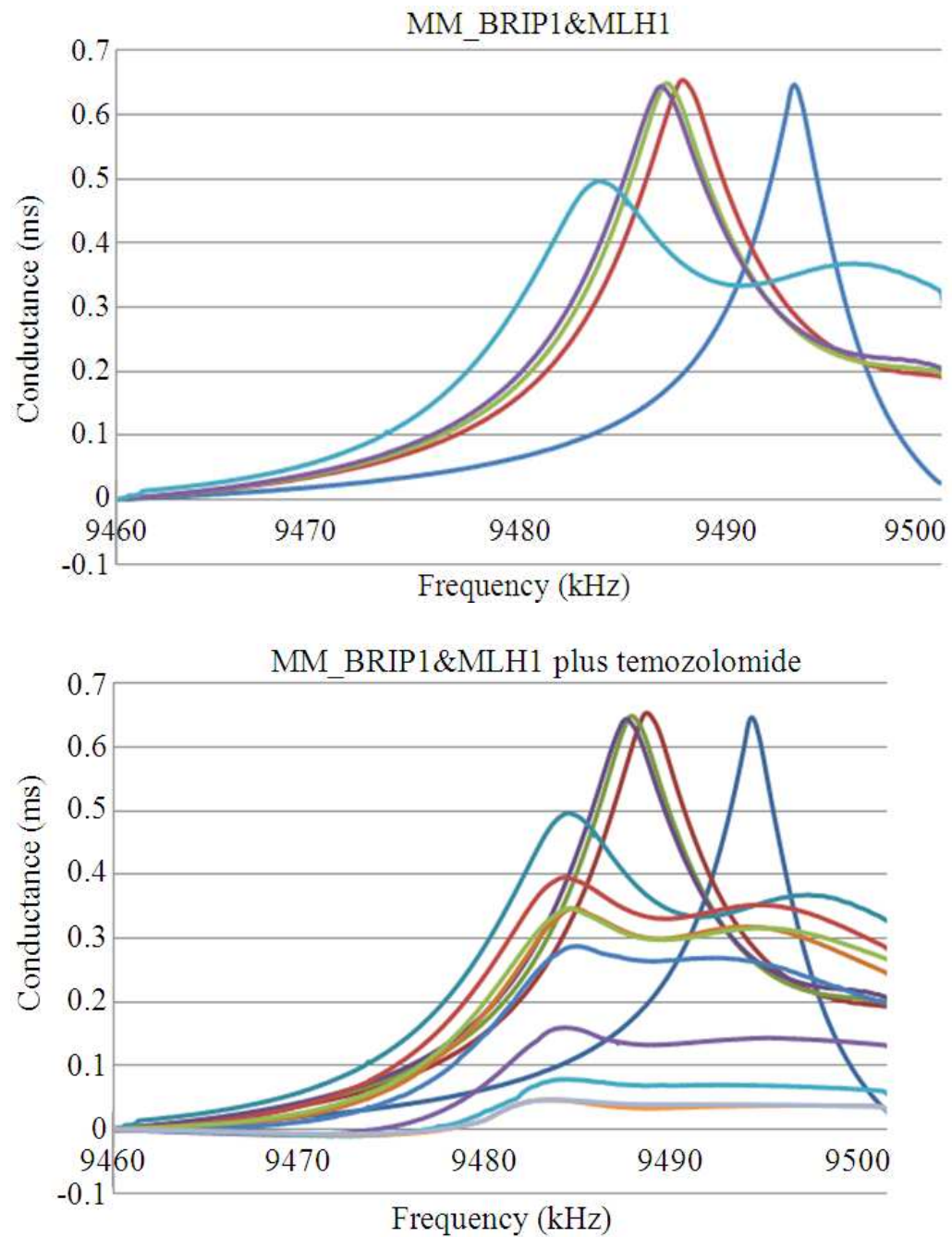

- Beginning

- IVTT addition

- IVTT addition $10 \mathrm{~min}$

- Post capture

- Post wash 


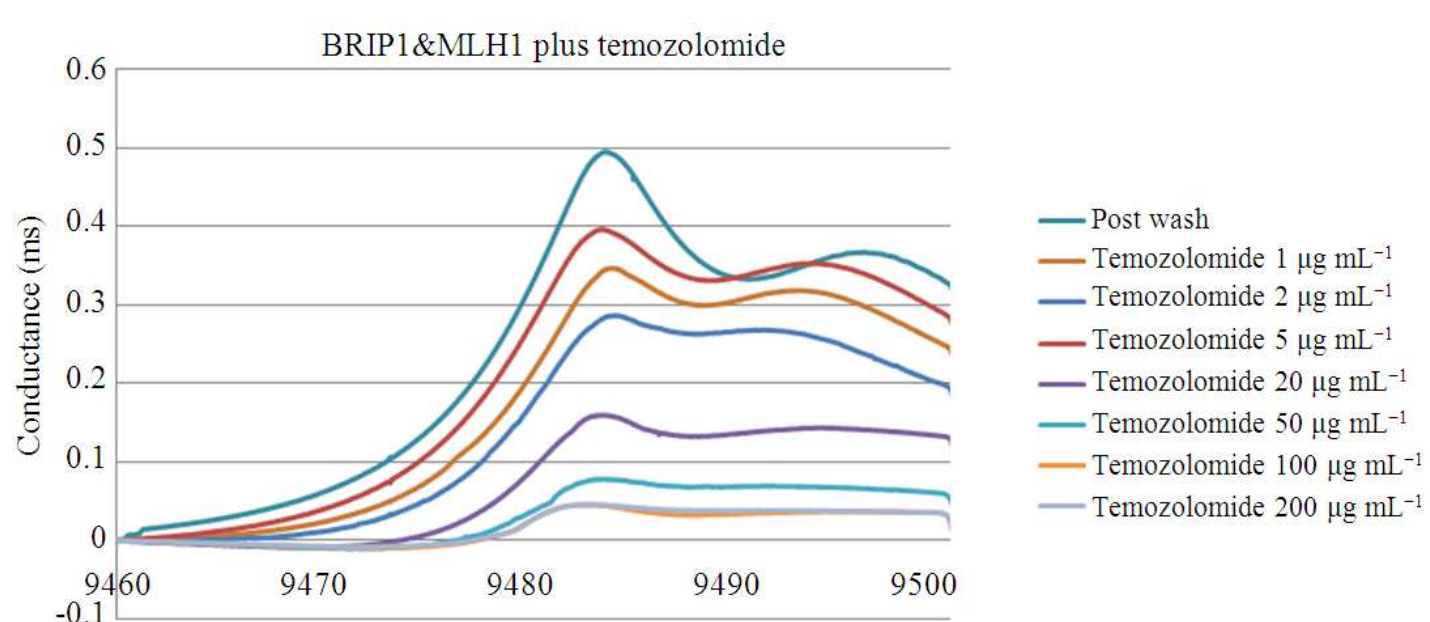

Frequency $(\mathrm{kHz})$

Fig. 5. Conductance curves of MM_BRIP1\&MLH1 expressing QC (upper panel). Conductance curves of MM_BRIP1\&MLH1 expressing QC plus Temozolomide (as multi-genes experiment) (intermediate and lower panel). The curves were collected in different steps of NAPPA process, as reported in the legends and after the addition of increasing concentration of Temozolomide
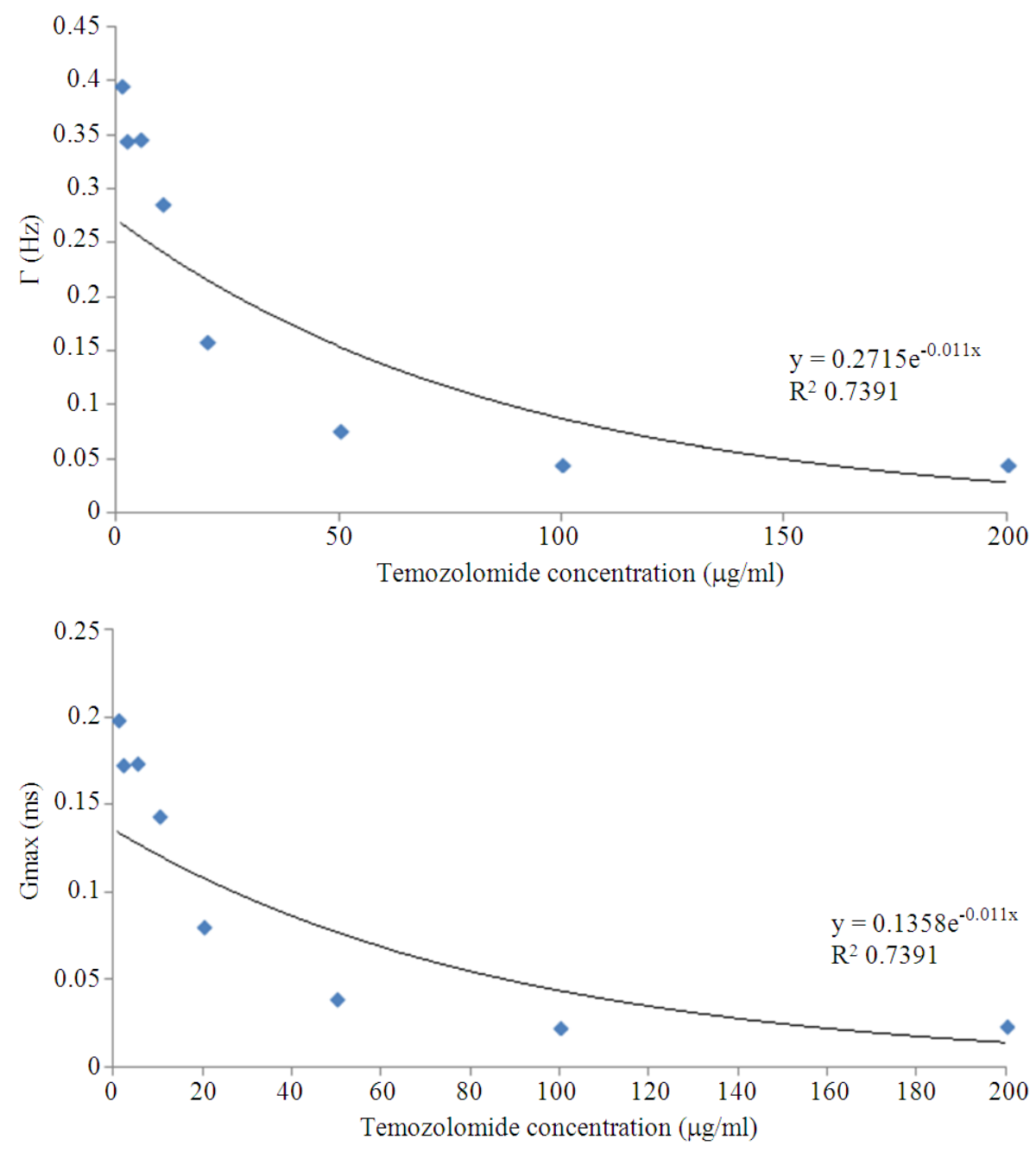

Fig. 6. Linear response to increasing doses of Temozolomide: Correlation between $\Gamma(\mathrm{Hz})$ and Temozolomide concentration $(\mu \mathrm{g} / \mathrm{ml})$ (upper panel); correlation between $\mathrm{G}_{\max }(\mathrm{mS})$ and Temozolomide concentration $(\mu \mathrm{g} / \mathrm{ml})$ (lower panel) 


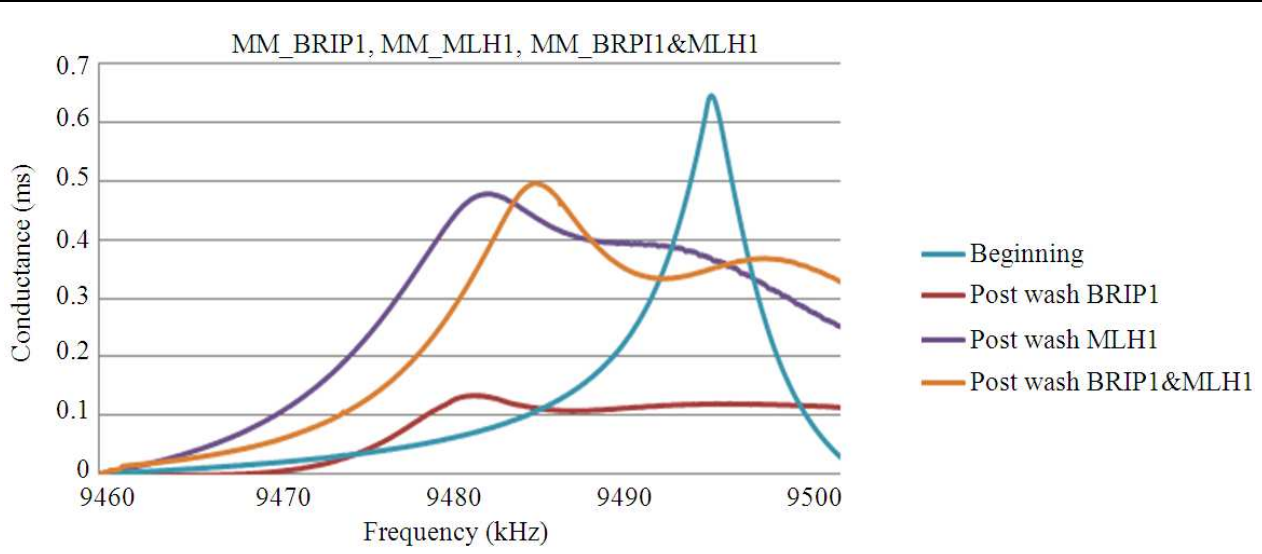

Fig. 7.Linear response to increasing doses of Temozolomide: Correlation between $\Gamma(\mathrm{Hz})$ and Temozolomide concentration $(\mu \mathrm{g} / \mathrm{ml})$ (upper panel); correlation between $\mathrm{G}_{\max }(\mathrm{mS})$ and Temozolomide concentration $(\mu \mathrm{g} / \mathrm{ml})$ (lower panel)

\section{Conclusion}

In this study, we introduced a new application of our previously described NAPPA-based nanoconductometric sensor, (Nicolini et al., 2012a; 2012b; Nicolini et al., 2013), which combined with Mass Spectrometry using SNAP arrays (Nicolini et al., 2013) has been extended to cancer studies (Bragazzi et al., 2014a), and in this context has been used to clinically screen patients respondent to TMZ from those refractory to this drug. We performed a positive control (TMZ plus MLH1 protein), a negative control (TMZ plus BRIP1 protein) and a multi-gene experiment (TMZ plus BRIP1\&MLH1 being co-expressed), showing that we are able to properly perform pharmacoproteomics tasks, discriminating each protein and drug unique conductance curve as well as their interactions, even in the presence of multi-proteins being immobilized. Moreover, in the last part of our paper, we used a multiple regression model in order to predict the behavior of TMZ when exposed to BRIP1\&MLH1 co-expressed and we showed that we are able to predict the drug-protein interaction profile with a good regression coefficient.

\section{Acknowledgement}

We are grateful to Dr. Fernanda Festa and Professor Josh Labaer at Arizona State University (ASU, USA) for providing the two genes immobilized on NAPPA array originally utilized in other context and reported in jointly published communications.

\section{Funding Information}

This project was supported by grants to Professor Claudio Nicolini of the University of Genova, Italy by the FIRB Nanobiosensors (ITALNANONET RBPR05JH2P_003) and by a grant Funzionamento to
Fondazione ELBA Nicolini from MIUR (Italian Ministry for Research and University).

\section{Author's Contributions}

$\mathrm{CN}$ and EP designed and carried out the original experiments, RS and NLB performed the QCM_D measurements, NLB and CN analyzed the data and wrote the paper finalized by $\mathrm{CN}$ alone.

\section{Ethics}

All the experiments are in vitro and therefore do not require ethical approval.

\section{References}

Adamson, C., O.O. Kanu, A.I. Mehta, C. Di and N. Lin et al., 2009. Glioblastoma multiforme: A review of where we have been and where we are going. Expert Opin. Invest. Drugs, 18: 1061-1083. DOI: 10.1517/13543780903052764

Beljebbar, A., S. Dukic, N. Amharref and M. Manfait, 2010. Ex vivo and in vivo diagnosis of C6 glioblastoma development by Raman spectroscopy coupled to a microprobe. Anal. Bioanal. Chem., 398: 477-87. DOI: 10.1007/s00216-010-3910-6

Brasuel, M., R. Kopelman, T.J. Miller, R. Tjalkens and M.A. Philbert, 2001. Fluorescent nanosensors for intracellular chemical analysis: Decyl methacrylate liquid polymer matrix and ion-exchange-based potassium PEBBLE sensors with real-time application to viable rat C6 glioma cells. Anal. Chem., 73: 2221-8. DOI: 10.1021/ac0012041

Bragazzi, N.L., E. Pechkova and C. Nicolini, 2014a. Proteomics and proteogenomics approaches for oral diseases. Adv. Protein Chem. Struct. Biol., 95: 12562. DOI: 10.1016/B978-0-12-800453-1.00004-X 
Bragazzi, N.L., R. Spera, E. Pechkova and C. Nicolini, 2014b. NAPPA-based nanobiosensors for the detection of proteins and of protein-protein interactions relevant to cancer. J. Carcinog. Mutagen., 5: 166--166. DOI: 10.4172/21572518.1000166

Cantor, S.B. and J. Xie, 2010. Assessing the link between BACH1/FANCJ and MLH1 in DNA crosslink repair. Environ. Mol. Mutagen, 51: 500-7.

Chen, X.C., Y.L. Deng, Y. Lin, D.W. Pang and H. Qing et al., 2008. Quantum dot-labeled aptamer nanoprobes specifically targeting glioma cells. Nanotechnology, 19: 235105-235105. DOI: 10.1088/0957-4484/19/23/235105

Cheng, C.I., Y.P. Chang and Y.H. Chu, 2012. Biomolecular interactions and tools for their recognition: Focus on the quartz crystal microbalance and its diverse surface chemistries and applications. Chem. Soc. Rev., 41: 1947-71. DOI: 10.1039/C1CS15168A

Cobbs, C.S., 2013. Cytomegalovirus and brain tumor: Epidemiology, biology and therapeutic aspects. Curr. Opin. Oncol., 25: 682-8. DOI: 10.1097/CCO.0000000000000005

Desai, A., W.S. Kisaalita, C. Keith and Z.Z. Wu, 2006. Human neuroblastoma (SH-SY5Y) cell culture and differentiation in 3-D collagen hydrogels for cellbased biosensing. Biosens. Bioelectron., 21: 148392. DOI: 10.1016/j.bios.2005.07.005

Dixon, M.C., 2008. Quartz crystal microbalance with dissipation monitoring: enabling real-time characterization of biological materials and their interactions. J. Biomol. Tech., 19: 151-8.

Dubrow, R. and A.S. Darefsky, 2011. Demographic variation in incidence of adult glioma by subtype, United States, 1992-2007. BMC Cancer, 11: 325325. DOI: $10.1186 / 1471-2407-11-325$

Furnari, F.B., T. Fenton, R.M. Bachoo, A. Mukasa and J.M. Stommel et al., 2007. Malignant astrocytic glioma: genetics, biology and paths to treatment. Genes Dev., 21: 2683-710. DOI: $10.1101 / \mathrm{gad} .1596707$

Gottlieb, A. and R.B. Altman, 2014. Integrating systems biology sources illuminates drug action. Clin. Pharmacol. Ther., 95: 663-9. DOI: 10.1038/clpt.2014.51

Hunter, A.C., 2009. Application of the quartz crystal microbalance to nanomedicine. J. Biomed. Nanotechnol., $\quad 5: \quad 669-75 . \quad$ DOI: 10.1166/jbn.2009.1083

Jain, K.K., 2004. Role of pharmacoproteomics in the development of personalized medicine. Pharmacogenomics, 5: 331-6. DOI: 10.1517/phgs.5.3.331.29830
Malmer, B., P. Adatto, G. Armstrong, J. Barnholtz-Sloan and J.L. Bernstein et al., 2007. GLIOGENE an international consortium to understand familial glioma. Cancer Epidemiol. Biomarkers Prev., 16: 1730-4. DOI: 10.1158/1055-9965.EPI-07-0081

Manning, P., C.J. McNeil, J.M. Cooper and E.W. Hillhouse, 1998. Direct, real-time sensing of free radical production by activated human glioblastoma cells. Free Radic. Biol. Med., 24: 1304-9. DOI: 10.1016/S0891-5849(97)00455-3

Megova, M., J. Drabek, V. Koudelakova, R. Trojanec and O. Kalita et al., 2014. Isocitrate dehydrogenase 1 and 2 mutations in gliomas. J. Neurosci. Res., 92: 1611-1620. DOI: 10.1002/jnr.23456

Mirzoeva, O.K., T. Kawaguchi and R.O. Pieper, 2006. The Mre11/Rad50/Nbs1 complex interacts with the mismatch repair system and contributes to temozolomide-induced $\mathrm{G}_{2}$ arrest and cytotoxicity. Mol. Cancer Ther., 5: 2757-66. DOI: 10.1158/15357163.MCT-06-0183

Nicolini, C., M. Adami, M. Sartore, N.L. Bragazzi and V. Bavastrello et al., 2012a. Prototypes of newly conceived inorganic and biological sensors for health and environmental applications. Sensors, 12: 17112-27. DOI: 10.3390/s121217112

Nicolini, C., N. Bragazzi and E. Pechkova, 2012b. Nanoproteomics enabling personalized nanomedicine. Adv. Drug Deliv. Rev., 64: 1522-31. DOI: 10.1016/j.addr.2012.06.015

Nicolini, C., R. Spera, F. Festa, L. Belmonte, S. Chong, J. Labaer and E. Pechkova, 2013. Mass Spectrometry and Florescence Analysis of Snap-Nappa Arrays Expressed Using E. coli Cell_Free Expression System. J. Nanomed. Nanotech., 4: 181-195. DOI: 10.4172/2157-7439.1000181

Ning, J. and H. Wakimoto, 2014. Oncolytic herpes simplex virus-based strategies: Toward a breakthrough in glioblastoma therapy. Front Microbiol., 5: 303-303. DOI: 10.3389/fmicb.2014.00303

Noushmehr, H., D.J. Weisenberger, K. Diefes, H.S. Phillips and K. Pujara et al., 2010. Identification of a $\mathrm{CpG}$ island methylator phenotype that defines a distinct subgroup of glioma. Cancer Cell, 17: 51022. DOI: 10.1016/j.ccr.2010.03.017

Ostrom, Q.T., L. Bauchet, F.G. Davis, I. Deltour and J.L. Fisher et al., 2014. The epidemiology of glioma in adults: A "state of the science" review. Neuro Oncol. 16: 896-913. DOI: 10.1093/neuonc/nou087

Patel, A.P., I. Tirosh, J.J. Trombetta, A.K. Shalek and S.M. Gillespie et al., 2014. Single-cell RNA-seq highlights intratumoral heterogeneity in primary glioblastoma. Science, 344: 1396-401. DOI: 10.1126/science. 1254257 
Penrod, N.M. and J.H. Moore, 2014. Data science approaches to pharmacogenetics. Curr. Mol. Med., 14: 805-813. DOI: $10.2174 / 1566524014666140811112438$

Querfeld, C., S.T. Rosen, J. Guitart, A. Rademaker and D.S. Pezen et al., 2011. Multicenter multicenter phase II trial of temozolomide in mycosis fungoides/sézary syndrome: Correlation with $\mathrm{O}^{6}$ methylguanine-DNA methyltransferase and mismatch repair proteins. Clin. Cancer Res., 17: 5748-54. DOI: 10.1158/1078-0432.CCR-11-0556

Robert, J., V. Le Morvan, E. Giovannetti and G.J. Peters, 2014. On the use of pharmacogenetics in cancer treatment and clinical trials. Eur J Cancer, 50: 25322543. DOI: 10.1016/j.ejca.2014.07.013, PMID: 25103456

Rodriguez-Hernandez, I., S. Perdomo, A. Santos-Briz, J.L. Garcia and J.A. Gomez-Moreta et al., 2014. Analysis of DNA repair gene polymorphisms in glioblastoma. Gene, 536: 79-83. DOI: 10.1016/j.gene.2013.11.077

Sandrone, S.S., G. Repossi, M. Candolfi and A.R. Eynard, 2014. Polyunsaturated fatty acids and gliomas: A critical review of experimental, clinical and epidemiologic data. Nutrition, 30: 1104-1109. DOI: 10.1016/j.nut.2014.01.009

Shinsato, Y., T. Furukawa, S. Yunoue, H. Yonezawa and K. Minami et al., 2013. Reduction of MLH1 and PMS2 confers temozolomide resistance and is associated with recurrence of glioblastoma. Oncotarget, 4: 2261-70. PMID: 24259277

Spera, R., F. Festa, N.L. Bragazzi, E. Pechkova and J. LaBaer et al., 2013. Conductometric monitoring of protein-protein interactions. J. Proteome Res., 12: 5535-47. DOI: 10.1021/pr400445v

Stark, A.M., A. Doukas, H.H. Hugo and H.M. Mehdorn, 2010. The expression of mismatch repair proteins MLH1, MSH2 and MSH6 correlates with the Ki67 proliferation index and survival in patients with recurrent glioblastoma. Neurol. Res., 32: 816-20. DOI: 10.1179/016164110X12645013515052

Stupp, R., W.P. Mason, M.J. van den Bent, M. Weller and B. Fisher et al., 2005. Radiotherapy plus concomitant and adjuvant temozolomide for glioblastoma. N Engl. J. Med., 352: 987-96. DOI: 10.1056/NEJMoa043330

Thakkar, J.P., T.A. Dolecek, C. Horbinski, Q.T. Ostrom and, D.D. Lightner et al., 2014. Epidemiologic and molecular prognostic review of glioblastoma. Cancer Epidemiol. Biomarkers Prev., 23: 19851996. PMID: 25053711
Thon, N., S. Kreth and F.W. Kreth, 2013. Personalized treatment strategies in glioblastoma: MGMT promoter methylation status. Onco Targets Ther., 6: 1363-72. DOI: 10.2147/OTT.S50208

Trevin, S., Y. Kataoka, R. Kawachi, H. Shuto and K. Kumakura et al., 1998. Direct and continuous electrochemical measurement of noradrenalineinduced nitric oxide production in C6 glioma cells. Cell Mol. Neurobiol., 18: 453-8. DOI: 10.1023/A:1022509901551

Valero, T., G. Moschopoulou, S. Kintzios, P. Hauptmann and M. Naumann et al., 2010. Studies on neuronal differentiation and signalling processes with a novel impedimetric biosensor. Biosens Bioelectron., 26: 1407-13. DOI: 10.1016/j.bios.2010.07.066

Vidone, M., F. Alessandrini, G. Marucci, A. Farnedi and D. de Biase et al., 2014. Evidence of association of human papillomavirus with prognosis worsening in glioblastoma multiforme. Neuro Oncol., 16: 298302. DOI: $10.1093 /$ neuonc/not140

von Bueren, A.O., M.D. Bacolod, C. Hagel, K. Heinimann and A. Fedier et al., 2012. Mismatch repair deficiency: A temozolomide resistance factor in medulloblastoma cell lines that is uncommon in Primary medulloblastoma tumours. Br. J. Cancer, 107: 1399-408. DOI: 10.1038/bjc.2012.403

Weathers, S.P. and M.R. Gilbert, 2014. Advances in treating glioblastoma. F1000Prime Rep., 6: 46-46. DOI: $10.12703 /$ P6-46

Witzmann, F.A. and R.A. Grant, 2003. Pharmacoproteomics in drug development. Pharmacogenom. J., 3: 69-76. DOI: 10.1038/sj.tpj.6500164

Xie, L., X. Ge, H. Tan, L. Xie and Y. Zhang et al., 2014. Towards structural systems pharmacology to study complex diseases and personalized medicine. PLoS Comput. Biol., 10: e1003554-e1003554. DOI: 10.1371/journal.pcbi.1003554

Zakir Hossain, S.M., H. Shinohara, F. Wang and H. Kitano, 2007. Real-time detection of L-glutamate released from C6 glioma cells using a modified enzyme-luminescence method. Anal. Bioanal. Chem., 389: 1961-6. DOI: 10.1007/s00216-0071569-4

Fee, C.J., 2013. Label-Free, Real-Time Interaction and Adsorption Analysis 2: Quartz Crystal Microbalance. In: Protein Nanotechnology, Gerrard, J.A. (Ed.), Humana Press, pp: 313-22. 